Daniel Carrasco - Daniel Lemus, Partido de masas y renovación de las elites: los casos de México y China / Mass party and renewal of elites: Mexico and China, Revista Izquierdas, 27, abril 2016, ISSN 0718-5049, pp. 63-86

\title{
Partido de masas y renovación de las elites: los casos de México y China
}

\author{
Mass party and renewal of elites: Mexico and China
}

\author{
Daniel Carrasco Brihuega y Daniel Lemus Delgado *
}

\footnotetext{
* Mexicano, Doctor en Ciencia Política. PhD Instituto de Estudios Políticos de Grenoble, Francia - Profesor-Investigador de la Escuela Nacional de Humanidades y Ciencias Sociales del Tecnológico de Monterrey. dcarrascob@itesm.mx. **Mexicano, Doctor en Relaciones Internacionales Transpacíficas de la Facultad de Economía, Universidad de Colima. Profesor-Investigador de la Escuela Nacional de Humanidades y Ciencias Sociales del Tecnológico de Monterrey. dlemus@itesm.mx
} 


\section{Resumen:}

Este artículo analiza la relación entre los procesos de renovación de las elites y los partidos de masas a partir de la transformación histórica del PRI y PCCH. Estos casos son explorados desde la teoría de las elites políticas propuesta por Michels, la cual sostiene que existe una elite que controla, dirige y organiza al partido y con ello a la vida política del país con la intención de mantener sus intereses de grupo. Así, se concluye enfatizando la manera en que los partidos de masas son un mecanismo de renovación de las elites.

Palabras claves: Renovación de las elites Partido de masas - Partido Revolucionario Institucional - Partido Comunista Chino

\begin{abstract}
:
This article analyzes the relationship between political elites and mass parties. Thus, we consider the historical transformation of the Institutional Revolutionary party and Chinese Communist party. We analyze these cases from the political elite theory proposed by Michels. This theory suggests that elites control, manage and organize the party and thus the political life of the country. So, elites seek maintain their own interests. Thus, we concluded that mass parties are a mechanism for renewal of elites.
\end{abstract}

Keywords: Renewal of elites-Mass PartyInstitutional Revolutionary Party- Chinese Communist Party

Recibido: 23 octubre 2015

Aceptado: 3 enero 2016

\section{Introducción}

El verano del 2012 marcó el regreso del Partido Revolucionario Institucional (PRI) a la Presidencia de la República en México, después de doce años de gobierno de centro derecha, el Partido Acción Nacional. De esta manera, regresaba al poder el partido que había gobernado ininterrumpidamente los destinos de la nación mexicana durante setenta y un años, desde su fundación en 1929. Este caso era percibido como el regreso de las tradicionales elites políticas a través de un proceso electoral que permitía recuperar al PRI la presidencia de la República en la figura de Enrique Peña Nieto ${ }^{1}$. A finales de ese mismo año se celebró el decimoctavo Congreso Nacional del Partido Comunista Chino (PCCh), en el cual se determinó la sucesión de los máximos líderes de la República Popular China. En este congreso se eligieron a los siete miembros del Comité Central del Partido, entre los que se encontraban el presidente Xi Jinping y el primer ministro Li Keiqiang. Así, se dio paso a la transición de la llamada quinta generación de líderes políticos de China que gobernará este país por los siguientes diez años. Por medio de este acto, el PCCh garantizó su continuidad en el poder, el cual ejerce de manera ininterrumpida desde el triunfo de la Revolución Comunista en 1949.

\footnotetext{
${ }^{1}$ Es importante que en sus orígenes, en el año de 1929, el primer nombre del partido fue Partido Nacional Revolucionario, cambiando posteriormente a Partido de la Revolución Mexicana; finalmente, en el año de 1946 este partido adoptó su nombre actual, Partido Revolucionario Institucional. 
Daniel Carrasco - Daniel Lemus, Partido de masas y renovación de las elites: los casos de México y China / Mass party and renewal of elites: Mexico and China, Revista Izquierdas, 27, abril 2016, ISSN 0718-5049, pp. 63-86

Los casos de las elites gobernantes en China y México se enmarcan en su pertenencia a partidos políticos de masas. De esta manera, el partido se ha convertido en el principal instrumento para mantener en el poder, así como ordenar, coordinar y permitir los procesos de renovación de las elites políticas. En ambos casos, se trata de dos partidos de masas que surgieron teniendo como antecedente un proceso revolucionario que aspiraba modernizar políticamente ambos países. En efecto, la Revolución Mexicana de 1910 y la Primera Revolución China de 1911 fueron concebidas como alternativas para la superar la inoperancia e incapacidad de la vieja elite para transitar hacia una modernización política. Estos procesos revolucionarios fueron los condicionantes para que, más tarde, surgieran y se consolidaran el PRI y el PCCh como partidos de masas.

La gran paradoja es el hecho de que los partidos que surgieron al amparo de dichos procesos revolucionarios terminaron bajo la conducción de una pequeña elite, que se mantiene y perpetúa en el poder durante décadas, cuando originalmente fueron fundados como un mecanismo para erradicar los privilegios y prebendas de las elites del Antiguo Régimen. Así, la pregunta que surge es: ¿Por qué existe un abandono al ideario fundacional de estos partidos por crear una nueva sociedad en la cual se finalizara con los beneficios que gozaban las elites políticas que acaparaban el poder? Nosotros sugerimos que para comprender estos procesos es necesario introducir una visión histórica comparada que permita reconocer la manera en que la legitimidad política de las elites se construyó sobre procesos históricos que privilegiaron la reinvención de las elites. Esta reinvención ocurrió en gran medida a partir de la apropiación de un discurso modernizador, el cual alejó los partidos políticos de sus principios fundacionales.

Este artículo tiene como intención analizar la renovación de las elites políticas en el contexto de partidos de masas considerando los casos del PRI y el PCCh. El punto de partida es el supuesto que en el contexto de partidos hegemónicos -México- o partidos de Estado - China- ha sido posible renovar las elite gobernantes por mecanismos previamente conocidos y aceptados por todos los actores políticos importantes al interior del partido. En otras palabras, nosotros sugerimos que en un proceso dinámico e intersubjetivo, las elites han sido capaces de reinventarse a sí mismas cuando aceptan los códigos de acceso y permanencia a las elites, pero al mismo tiempo transforman dichos códigos en la medida en que se empoderan y se renuevan obteniendo su legitimidad. Una parte fundamental de esta legitimidad es la creación y difusión de un discurso modernizador. Por lo tanto, en México y China podemos presenciar como los partidos de masas han permitido la permanencia de las elites políticas con profundo pragmatismo que les ha alejado notablemente de sus principios fundacionales pero que, al mismo tiempo, les ha permitido establecer y consolidar mecanismos para la permanencia en el poder.

Así, este artículo se basa en el supuesto teórico de la permanencia de las elites que propone Michels el cual sostiene que existe un grupo de personas que controla, dirige y organiza al partido, y con ello a la vida política de un país, con la intención de mantener sus intereses de grupo. Desde nuestra perspectiva, un elemento importante en este proceso lo constituye el discurso modernizador que ha funcionado como pegamento entre un ideario siempre inacabado -la modernidad- y los mecanismos de participación al interior del partido. En otras palabras, el discurso es importante porque justifica y legitima, al tiempo que es la pauta para la acción en los procesos de renovación de las elites. Es en nombre de 
Daniel Carrasco - Daniel Lemus, Partido de masas y renovación de las elites: los casos de México y China / Mass party and renewal of elites: Mexico and China, Revista Izquierdas, 27, abril 2016, ISSN 0718-5049, pp. 63-86

esta modernización como se han generado cambios que alejan a los partidos de sus principios fundacionales.

El presente artículo está organizado en cuatro grandes secciones. En la primera de ellas se comentan las características de las elites desde la teoría política. En la segunda sección se abordan los principios teóricos que permiten explicar los mecanismos de renovación de las elites al interior de los partidos políticos y su relación con el discurso de la modernidad. En la tercera sección se presentan los elementos más importantes del origen y transformación del PPCh y del PRI. Finalmente, a manera de conclusión, en la última sección se discuten los procesos de renovación de las elites en una perspectiva comparada. En este apartado enfatizamos que la estructura organizacional del partido de masas, cobijada bajo el discurso modernizador, es la que permite la permanencia y la renovación de las elites políticas.

\section{La teoría de las elites}

La teoría de las elites demuestra que en todas las sociedades existen dos grupos de personas: los gobernantes y los gobernados. El primer grupo es mucho menos numeroso que el segundo y está considerado como un grupo restringido que posee características relativamente similares. Esta perspectiva "elitista" ha existido durante siglos, pero es hasta el siglo XIX cuando se sistematizó y se postuló que en todo sistema político, el grupo de los gobernantes, considerado como la elite política, dispone del poder y toma las decisiones políticas más importantes de la sociedad.

El análisis clásico de las elites ha sido bosquejado por tres autores: Mosca, Pareto y Michels. Para Mosca, todo sistema político está compuesto de dos estratos: la clase política y la clase no política. Los conceptos dominantes de su análisis son los siguientes: la elite es parte de la clase política y está presente en todas las sociedades, desde las menos desarrolladas y civilizadas hasta las más avanzadas y poderosas. Existen dos clases de personas, una clase que gobierna y otra que es gobernada. La primera que es siempre la menos numerosa, asume todas las funciones políticas, monopoliza el poder y goza de ventajas que le son propias, mientras que la segunda, la más numerosa es controlada y dirigida por la primera ${ }^{2}$.

Esta minoría se caracteriza también por estar organizada y consciente de ser una clase social. Es inevitable la dominación de la minoría organizada sobre la mayoría desorganizada. Mientras más grande es la comunidad política, la minoría gobernante será proporcionalmente más pequeña en relación con ella, y más difícil le será a la mayoría organizarse o resistirse contra la minoría ${ }^{3}$.

Sin embargo, esta elite permanece estratificada en el centro del grupo dirigente de los jefes superiores. Esta elite puede ser abierta o cerrada. En el primer caso se trata de una elite "democrática" y en el segundo de una elite "aristocrática". Mosca subraya que las democracias modernas favorecen la circulación de las elites, contrariamente a los Estados absolutistas. Las elites políticas, una pieza esencial de la historia de los países, tienen

\footnotetext{
2 Norberto Bobbio et al., "Teoría de las elites”, en Diccionario de Política, México, D.F., Siglo XXI, 2006, p. 520.

3 Ibid, 522.
} 
Daniel Carrasco - Daniel Lemus, Partido de masas y renovación de las elites: los casos de México y China / Mass party and renewal of elites: Mexico and China, Revista Izquierdas, 27, abril 2016, ISSN 0718-5049, pp. 63-86

tendencia a gobernar en función de sus intereses propios y no en función del interés del conjunto de la población.

Para Pareto, la elite se define como un grupo de individuos que cuentan con el grado más alto de competencia en su campo de actividad. No obstante, esta elite está dividida en dos, la elite gobernante y la elite no gobernante. A través de la elite gobernante de Pareto encontramos la clase política de Mosca. La pertenencia a la elite no corresponde forzosamente a la herencia, los niños no heredan forzosamente las cualidades de los padres, y, por lo tanto, la renovación de la elite se lleva a cabo por un reemplazamiento de las elites antiguas por las elites nuevas: "este fenómeno de nuevas elites que por un movimiento incesante de circulación en el que surgen capas superiores y después caen en decadencia, son minimizadas y desaparecen, éste es uno de los principios de la historia y es indispensable tenerlo en cuenta para comprender los grandes movimientos sociales" ${ }^{\text {. }}$

Por su parte Michels asevera que todo partido político está organizado de manera oligárquica, en donde la autoridad se encuentra entre las manos de algunas personas o de algunas familias poderosas, la oligarquía. Para Michels, son tres razones las que explican este hecho; en primer lugar, el inevitable advenimiento de los especialistas en el seno de los partidos políticos; una segunda razón radica en la estructura misma de la oligarquía; por último, la voluntad misma por mantener esta oligarquía ${ }^{5}$. Para Michels el sistema democrático conduce obligadamente a la oligarquía y refiriéndose específicamente al partido democrático moderno, concepto que nos ocupa en este trabajo; el autor de los partidos políticos*, hace un análisis militarista del partido político moderno entendiéndose éste como una organización de lucha en el sentido político del término que se adapta a la dimensión de las acciones y estrategias. En este sentido el partido político implica una mayor organización lo cual produce una estructura jerárquica y centralizada en la toma de decisiones; fenómeno que pone en evidencia los comités directivos de los dos partidos políticos aquí comparados.

Para Michels el partido democrático moderno puede practicar una política estatal democrática pero a medida que su propia organización va aumentando, su capacidad se ajusta a un control oligárquico. Prioriza la ampliación del poder incorporando al mayor número posible de miembros, terminando como una organización metódica de masas electorales que procura a sus miembros con el fin de obtener votos. Entonces, la organización como tal se transforma en un fin y no en un medio.

Los casos del Partido Revolucionario Institucional y del Partido Comunista Chino, en México y China respectivamente, distinguidos por "revolucionarios", una vez que obtienen el poder, se consolidan políticamente, ambos se organizan de manera conservadora, ya no representan a una organización contestataria dejan de ser oposición al sistema político y se transforman en la pieza fundamental del sistema político que compite y simula en el periodo estudiado, competir por el poder.

En su referencia a las masas, Michels explica que éstas hacen desaparecer al individuo, por su indiferencia política se hacen impotentes e incapaces de adoptar resoluciones, resultan fáciles de dominar y por lo tanto necesitan una dirección, una guía que pueda hablar por ellas, de esta manera los líderes se vuelven indispensables en la

\footnotetext{
4 Dominique Chagnollaud, "Les théories des élites”, en Sociologie Politique, París, Dalloz, 2000.

5 Robert Michels, Les Partis politiques: essai sur les tendances oligarchiques des démocraties, París, Flammarion, 1971.
} 
Daniel Carrasco - Daniel Lemus, Partido de masas y renovación de las elites: los casos de México y China / Mass party and renewal of elites: Mexico and China, Revista Izquierdas, 27, abril 2016, ISSN 0718-5049, pp. 63-86

organización y dirección del partido y es por este motivo que el partido se identifica con el líder, sin embargo los líderes mantienen una evidente independencia de las masas. La organización de un grupo restringido de personas en la cúpula del partido político será la única que desde el rol de delegados podrá conducir políticamente los destinos del Estado. De esta forma y dentro de las características establecidas por Michels del partido político moderno existen luchas entre los líderes inter-partidarios que se mezclan con la lucha intrapartidaria y la renovación de las dirigencias son simples simulaciones, puesto que los liderazgos a vincularse y formar una amalgama política que reúna nuevamente a las élites con una significativa independencia de las masas. Por su parte las masas poseen el derecho de fiscalizar y destituir a los líderes, sin embargo estos derechos se convierten en una ilusión cuando prevalece el poder de la oligarquía en el ejercicio del poder, ya que en la realidad los líderes por su naturaleza propia cuentan con alto grado de independencia.

En otra perspectiva de análisis, Mills en la elite en el poder, analiza la estructura del poder en Estados Unidos ${ }^{6}$. Mills pone en relieve la dominación de una "elite del poder", la cual cumple ciertas funciones o roles. Los poseedores de estos roles ejercen su hegemonía en tres sectores claves, lo que denomina tres “jerarquías institucionales". Estas instituciones son centrales en la sociedad americana: la institución política, la institución militar y la institución económica. Aquellos que están situados en lo más alto, en la cumbre de estas tres jerarquías ocupan "los puestos de comando estratégico de la estructura social" o constituyen lo que Mills nomina "el triángulo del poder". Miembros del directorio político, señores de la guerra, empresarios magnates, concentran cada uno en su área el poder de decisión nacional, comandando también así la estructura social. Estas tres elites son a pesar de su diferencia, solidarias entre ellas. Por otra parte, estas elites se encuentran vinculadas por intereses comunes, "afinidades psicológicas" intercambiables; es decir, que los miembros de las elites reciben formaciones similares y tienen orígenes sociales iguales, ello constituye un factor primordial en la conformación de una sola elite. Mills insiste que la circulación de los dirigentes entre estos tres sectores resulta el elemento esencial de la unidad de la elite ${ }^{7}$.

De manera contraria a la tesis de la unidad de las elites (Mosca, Pareto, Michels), las tesis pluralistas intentan demostrar que la complejidad de las estructura del poder genera distintas elites, asociadas y/o rivales. Robert Dahl, en una postura que refuta las tesis de Mills, llevó a cabo una encuesta empírica sobre los procesos de toma de decisiones de la ciudad americana de New Haven. A partir de esta encuesta Dahl defiende la tesis de la poliarquía fundada sobre la diversidad de las organizaciones, la dispersión de los recursos y el ejercicio de un poder político pluralista ${ }^{8}$.

Dahl, concentrándose en los procesos de decisión, intenta identificar los actores principales en tres aspectos de la vida municipal: urbanismo, educación pública y designación de candidatos. Dahl subraya que aunque el alcalde de la ciudad juega un rol clave, existe una diversidad de actores que intervienen durante todo el proceso de toma de decisiones. Así, el poder es repartido entre numerosos actores cuya influencia es variable en

\footnotetext{
6 Wright Mills. L'élite du pouvoir, Paris, La Découvert, 1969.

${ }^{7}$ Mills, op. cit.

8 Robert, Dahl, Who Governs?: Democracy and Power in an American City. New York, Yale University Press, 1961.
} 
Daniel Carrasco - Daniel Lemus, Partido de masas y renovación de las elites: los casos de México y China / Mass party and renewal of elites: Mexico and China, Revista Izquierdas, 27, abril 2016, ISSN 0718-5049, pp. 63-86

función de sus intereses ${ }^{9}$.

De esta forma, los recursos del poder no están concentrados en las manos de un sólo grupo, pero son distribuidos de manera desigual. Este hecho es el resultado de las diferencias entre las organizaciones sociales autónomas que intervienen en dicho proceso. De este pluralismo social emana la negociación y la competencia de un sistema pluralista. Dahl quiere también mostrar que esta poliarquía supone un mínimo de circulación de las elites, un consenso sobre las reglas democráticas del pluralismo, las organizaciones sociales y las desigualdades económicas. Desde esta perspectiva, New Haven cambió con la sociedad industrial y el sistema oligárquico, con el cual los recursos estaban concentrados, "ubicados bajo el esquema de la democracia". Por lo tanto, para Dahl no existe la elite dirigente, homogénea identificable por los intereses comunes ${ }^{10}$.

Estas perspectivas elitistas convergen en el proceso de toma de decisiones. En conjunto, intentan comprender de qué manera y por qué las elites toman sus decisiones. Otro interés de estas teorías es descubrir que las elites buscan ante todo reproducirse con el fin de conservar el poder. El presente estudio no escapa a este cuadro teórico "elitista". Sin embargo, en este trabajo, no limitaremos el estudio de los miembros del gobierno a la perspectiva elitista sino que estudiamos a las elites a partir del tiempo, es decir de su propia renovación en ambos países, vía los partidos políticos dominantes.

\section{Las elites desde el enfoque de los partidos políticos y el discurso de la modernidad como elemento justificador de las elites}

Como ya se mencionó Michels analiza el comportamiento de las elites en el marco de los partidos políticos, así como también la conducta de las masas en el juego del poder ${ }^{11}$. De esta manera, distingue claramente la influencia que tienen los dirigentes de los partidos políticos sobre las masas que se muestran incompetentes ante la capacidad de organización de las dirigencias o de las elites partidistas en este caso.

A partir de esta perspectiva, resulta indispensable la organización y la dirección del partido. Michels sostiene la hipótesis de que existe un liderazgo-profesional que separa a los gobernantes de los gobernados. Al igual que Mosca, defiende una superioridad moral de la clase política sobre las masas; sin embargo, Michels pone énfasis en la superioridad económica, histórica e intelectual que unos han adquirido sobre los otros ${ }^{12}$.

Se puede observar, tanto para China como para México que la dimensión organizacional del partido político es la variable fundamental que define su capacidad política y de representación durante décadas, dado que incide en la cohesión interna, determina e influye las grandes agrupaciones aliadas al partido y sus disciplinas son más pragmáticas sobre todo en cuanto a la movilización de los afiliados. Pero esto sucede en gran medida por un discurso ideológico que orienta la práctica política y, en última instancia, la permanencia y renovación de las elites. Particularmente, cuando se invoca la modernidad como proyecto político -ni importa si es una modernidad comunista o

\footnotetext{
${ }^{9}$ Dahl, op. cit.

10 Dahl, ibid.

11 Michels, op. cit.

12 Michels, Ibid.
} 
Daniel Carrasco - Daniel Lemus, Partido de masas y renovación de las elites: los casos de México y China / Mass party and renewal of elites: Mexico and China, Revista Izquierdas, 27, abril 2016, ISSN 0718-5049, pp. 63-86

capitalista- entendida como la posibilidad de alcanzar el progreso y bienestar, se construye un discurso de legitimidad bastante flexible que permitió alejarse de los principios fundacionales de ambos partidos. El reino del pragmatismo se implantó en la medida en que se justificó el quehacer político y, por lo tanto la razón de ser de la elite, desde la necesidad de alcanzar la modernidad.

Para nosotros, en los casos de China y México esto fue posible en gran medida por que el concepto mismo de la modernidad es un tanto escurridizo; es decir, se trata un término flexible que en contextos históricos específicos ha sido moldeado para responder a los intereses de las elites con la finalidad de perpetuarse en el poder.

En efecto, nosotros partimos de la definición de modernidad propuesta por Ellis que la considera como una condición, mentalidad o síndrome. Asimismo, propone que: “... los elementos de la condición moderna incluyen el rechazo de la autoridad tradicional, una noción progresista y no cíclica del tiempo, la emancipación individual y colectiva, una orientación ampliamente empirista hacia la comprensión del mundo, y una perspectiva prometeica que considera a todas las dificultades como problemas técnicos que pueden ser dominados a través de la actividad humana"13. Particularmente, en este artículo se enfatiza la idea de que la modernidad es al mismo tiempo un proyecto y una aspiración, cuyo cumplimiento gradual promete mejores condiciones de la vida frente a un presente que se muestra injusto e inadecuado y el cual es necesario superar desde el pensamiento racional aplicado a todos los campos del conocimiento.

El origen del término moderno, en su forma latina, fue por primera vez utilizado a fines del siglo $\mathrm{V}$ para diferenciar el presente, ya entonces oficialmente cristiano, del pasado considerado pagano ${ }^{14}$. La idea del cambio fue concebida como una de las más genuinas expresiones de la modernidad. Y entre más veloz fuera este cambio, más próximo se alcanzaría la gran promesa de la modernidad: el progreso ${ }^{15}$. La razón, el intelecto humano, la tecnología aplicada a los procesos productivos, los descubrimientos de la ciencia, la movilidad social, la participación de los gobernados en las decisiones del gobierno, en resumen, los resultados palpables de la modernidad, instalarían, tarde o temprano, a la población en una nueva tierra prometida. La modernidad era vista esencialmente como el triunfo de la razón, como una auténtica liberación y como un camino genuino hacia la revolución. La revolución entendida como cambio transformador ${ }^{16}$.

Desde su origen, la modernidad es, en primer lugar, una toma de conciencia sobre la ruptura con el pasado ${ }^{17}$. Es esta toma de conciencia es la que en sus orígenes definió el actuar de las elites políticas, tanto en China como en México. Desde sus orígenes, las elites del PCCh tuvieron en claro que era necesario una ruptura fundamental con el pasado para llevar al país a una nueva etapa en la historia que implicaba explícitamente la idea de mejores condiciones de vida para la población ${ }^{18}$. De esta manera, desde la perspectiva de

\footnotetext{
13 Elisabeth Ellis, “Modernity: Overview” en New Dictionary of History of Ideas, Detroit, Charles Scribner's Sons, 2005, 1473.

14 Jürgen Habermas, "Modernidad, un proyecto incompleto", en Nicolás Casullo (ed.), El Debate Modernidad Posmodernidad, Buenos Aires, El Cielo por Asalto, 1995, 131-144.

15 Marycela Córdova, "Modernidad, cultura y devenir del mundo actual", en Zidane Zaraoui (compilador), Modernidad y Posmodernidad: la crisis de los paradigmas y los valores, México, D.F, Editorial Limusa, 2000, 135-159.

16 Alain Touraine, Crítica de la Modernidad, México, D.F., Fondo de Cultura Económica, 2002.

17 Jaques Le Goff, Pensar la historia: modernidad, presente, progreso, Barcelona, Paidos, 1997.

18 Alan Lawrence, China under Communism, Londres, Routledge, 1998.
} 
Mao Zedong, considerado el padre fundador de la nueva China, la revolución implicaba la necesidad de luchar contra los "cuatro viejos" o las "cuatro cosas viejas": las viejas tradiciones, la vieja cultura, los viejos hábitos y las viejas ideas ${ }^{19}$. Al final de cuentas, no sólo se trataba de una lucha por el poder entre facciones, sino también una lucha de mentalidades por implantar una nueva forma de pensamiento que permitiera superar las ataduras del pasado.

En México, la idea de la ruptura con el pasado fue enmarcada en la institucionalización del poder, en un acuerdo que permitía un poder presidencial cuyo único límite parecía ser temporal. En efecto, el presidente, la máxima autoridad del país y su grupo cercano podía limitar y someter al poder legislativo y judicial, tanto a nivel nacional como provincial, con una única condición, se trataba de un poder limitado a un periodo presidencial. El concepto de la no reelección fue introducido como mecanismo para evitar la perpetuación en el poder de un solo hombre, como había ocurrido durante la dictadura de Porfirio Díaz. Durante este periodo que ha sido definido por Krauze como la presidencia imperial, cada presidente y la elite que lo acompañaba emprendieron a su manera acciones para modernizar al país en el terreno económico y social, dejando a un lado la modernización política entendida como la adopción de la democracia liberal ${ }^{20}$.

Si bien el caso de China y México no son trayectorias que se recorren para adoptar plenamente los valores y propuestas de la modernidad occidental, es posible afirmar que tanto el comunismo chino como los gobiernos posrevolucionarios en México no constituyeron un proyecto alterno, distinto, diferenciado en su esencia a lo que la modernidad representa. Es, ciertamente, una manera diferente de modernización. En otras palabras, un camino distinto para llegar a la modernidad. Pero tanto el liberalismo como el marxismo de corte maoísta o los gobiernos nacionalistas posrevolucionarios en México, constituyeron corrientes del pensamiento derivadas de un contexto moderno que buscaban los mismos propósitos: ruptura con el pasado, racionalización para comprender las estructuras que conforman al mundo, tecnificación como medio para incrementar la productividad, paradigma científico como fundamentación del mundo económico, político y social. Todo con el propósito de alcanzar el progreso. La modernización desde el comunismo o el nacionalismo revolucionario representaron un camino distinto para alcanzar uno de los grandes mitos de la modernidad, el progreso.

Es por esta razón que en China y México la modernización se constituyó en una poderosa base para la justificación ideológica que dio paso a la legitimidad política. En otras palabras, si en las sociedades tradicionales las personas que tenían el poder la fuente de legitimidad se encontraba en la relación con fuerzas sobrenaturales, más allá de la comprensión y la voluntad humana, con la modernidad se esperaba un uso racional del poder; es decir, la legitimidad se desprendía así de un ejercicio del poder que condujera a mejorar las condiciones de vida de la población en su conjunto. Este discurso es una pieza clave para comprender la durabilidad y vitalidad del PCCh y del PRI como partidos de masas.

Ahora bien, los partidos de masas se caracterizan por tener una organización sólida y una amplia base de afiliados que aportan económicamente al partido. Mantienen lazos

\footnotetext{
19 Jonathan D. Spence, The Search of Modern China, Nueva York: W.W. Norton \& Company, 1999.

${ }^{20}$ Enrique Krauze, La presidencia Imperial, México, D.F., TusQuest Editores, 2002.
} 
Daniel Carrasco - Daniel Lemus, Partido de masas y renovación de las elites: los casos de México y China / Mass party and renewal of elites: Mexico and China, Revista Izquierdas, 27, abril 2016, ISSN 0718-5049, pp. 63-86

fuertes con organizaciones externas como sindicatos, entidades religiosas y medios de comunicación. Según la clasificación de Duverger los partidos políticos se pueden clasificar en: nacionalistas (pluralistas o ultranacionalistas); socialistas (socialdemócratas o leninistas), y religiosos (confesionales o fundamentalistas) ${ }^{21}$. Evidentemente, en el caso de México se trata de un partido nacionalista que en su fundación compartía un programa social amplio que buscaba el beneficio de campesinos y obreros y que podría ser clasificado como de izquierda; mientras que, en el caso de China, se trató de un partido de inspiración leninista, pero con características chinas, ya que colocó como la base del partido la inmensa población campesina.

Estas características del liderazgo serán aquellas que aporten la conducción experta en el partido, y que hagan de su especialización técnica, un requisito indispensable para el colectivo. Es por este motivo que el partido se identifica con el líder, cuando en cualquier organización la oligarquía ha alcanzado un estado avanzado de desarrollo, los líderes comienzan a identificar consigo, no solo a las instituciones partidarias, sino también la dirección del partido y con ello el control de las masas.

En el caso de México desde su fundación el partido de Estado dio paso a una institucionalización de los caudillos revolucionarios al establecer un periodo sexenal de ejercicio absoluto del poder pero con reglas claras de renovación. Como se comentó anteriormente, en la medida que terminaba el periodo sexenal, se daba paso a otro grupo de personas que podrían representar a otras alas del partido de masas. En cambio, en China se observan dos momentos claves. El primer momento se caracterizó por la consolidación del poder absoluto en la figura de Mao. El segundo, a partir de la muerte de Mao se dio paso a una amplia transición con mecanismos de renovación que han permitido trasformaciones graduales al interior del partido. En la siguiente sección se compara, desde una perspectiva histórica, la manera en que esta visión del liderazgo partidista se desarrolló en el caso de China y de México.

\section{III.Legitimidad política y renovación de las elites: los casos de China y México}

\section{a) El Partido Comunista Chino y el arribo de la quinta generación}

El PCCh fue fundado en el año de 1921 por Chen Duxiu y Li Dazhao ${ }^{22}$. La fundación del partido fue consecuencia de la propagación de las ideas marxistas a partir del Movimiento del Cuatro de Mayo de 1919 y el creciente sentimiento sobre la necesidad de fundar un partido revolucionario para coordinar la lucha de los derechos populares ${ }^{23}$. Desde sus orígenes, la Unión Soviética animó la fundación del partido con la intención luchar contra

\footnotetext{
${ }^{21}$ Maurice Duverger, Los partidos políticos, México, D.F., Fondo de Cultura Económica, 1957.

22 Jan Palmwosky, Communist Party: China, en A Dictionary of Contemporary World History, Oxford, Reino Unido, Oxford University Press, 2008.

${ }^{23}$ Harriet Evans, Historia de China desde 1800, México, D.F., El Colegio de México, 1989.
} 
Daniel Carrasco - Daniel Lemus, Partido de masas y renovación de las elites: los casos de México y China / Mass party and renewal of elites: Mexico and China, Revista Izquierdas, 27, abril 2016, ISSN 0718-5049, pp. 63-86

el imperialismo, el feudalismo y el capitalismo ${ }^{24}$. El primer congreso se llevó a cabo en julio de 1921 en el cual participaron doce delegados representando a 57 miembros del partido de siete ciudades de China ${ }^{25}$. En 1922, bajo la influencia de la Internacional Comunista, la cúpula del partido decidió cooperar con el Kuomintang (KMT) liderado por el doctor Sun Yat-sen ${ }^{26}$. En sus orígenes, el partido se mostró poco atractivo para atraer miembros activos y para 1925 únicamente contaba con alrededor de 1.000 miembros; sin embargo, para el año de 1927, sobre la base de la organización sindical y bajo la influencia del creciente nacionalismo en China, el partido había reclutado ya alrededor de 50.000 miembros ${ }^{27}$. El creciente número de comunistas y su penetración en el movimiento obrero derivó en la represión y persecución de Jiang Jieshi, líder del KMT, quien identificó a los comunistas como el mayor peligro de China ${ }^{28}$. Por lo tanto, Jiang se dispuso a destruir el PCCh por medio de brutales masacres que ocurrieron en Shanghai y en otras partes de China en abril de $1927^{29}$.

El PCCh buscó refugio en el campo y estableció su base de operaciones en Jianxi en 1931. Este fue el hecho clave que permitió su transformación en del partido en un partido de masas, con alrededor de 300.000 miembros $^{30}$. El refugio en Jianxi posibilitó que la elite ganara experiencia en el gobierno y en la organización del partido. Asimismo, en este periodo se establecieron las bases para el desarrolló un ejército eficaz, el cual significaría a la postre un elemento fundamental para ganar la guerra civil.

En el año 1934 ante el acoso del ejército nacionalista, alrededor de 100.000 soldados del Ejército Rojo Comunista embarcaron en la épica Gran Marcha de 6.000 millas $^{31}$. Durante este acontecimiento, Mao Zedong afirmó su liderazgo al interior del partido. La Larga Marcha transformó el partido de ser un movimiento urbano incipiente a un partido de masas con una amplia base campesina. Al concluir la Larga Marcha los comunistas establecieron por una década su base principal de operaciones en Yan'an. La permanencia en Yan'an significó un periodo de regeneración y crecimiento del partido, así como representó un momento crucial para consolidar la ideología partidista y la construcción de una narrativa que estableció el mito fundacional del partido ${ }^{32}$. Particularmente, en Yan'an se echaron raíces para el culto de la figura de Mao y el establecimiento de elite política que continuaría al frente del partido hasta la década de $1990^{33}$. Entre las herencias de la permanencia en Yan'an, se encuentra la idea de dinamismo

\footnotetext{
24 Xiaowei Zang, "Government and changing social relations", en Xiaowei Zang, (ed.), Understanding Chinese Society, Londres, Routledge, 2013, 170-182.

25 Stephen Uhalley, A History of the Chinese Communist Party, Stanford, California, Stanford University Press, 1988

${ }^{26}$ Lauwrence, op. cit.

27 Palmwosky, op. cit.

28 Evans, op. cit.

${ }^{29}$ Robert André Lafleur, "History”. En Robert André Lafleur, (ed.), Asia in Focus: China, Santa Barbara, California, ABC-Clio, 2010, 21-66.

30 Palmwosky, Ibid.

31 Jonathan Fenby, History of Modern China: The Fall and Rise of a Great Power, 1850 to the present, Londres, Penguin Books, 2013.

32 Orville Schell y John Delury, Wealth and Power: China's Long March to the Twenty First Century, Nueva York, Random House, 2013.

33 Kenneth Lieberthal, Governing China: From Revolution Through Reform, Nueva York, W.W. Norton \& Company, 1995.
} 
Daniel Carrasco - Daniel Lemus, Partido de masas y renovación de las elites: los casos de México y China / Mass party and renewal of elites: Mexico and China, Revista Izquierdas, 27, abril 2016, ISSN 0718-5049, pp. 63-86

y cambio revolucionario, así como la disciplina estricta al interior del partido, elementos que estarían presente en las décadas posteriores.

En el año de 1945, al llegar a su fin la invasión japonesa, el partido contaba ya con alrededor de un millón de miembros. Este número triplicó para el final de la guerra civil, cuando en octubre de 1949 se fundó la República Popular China. Los siguientes años y hasta la muerte en 1997 Deng Xiaoping, las decisiones más importantes del Partido Comunista y de China, como había sucedido en la época de Mao, recaían más en un solo hombre. Sin embargo, a partir de Jiang Zemin, se dio pasó a un estilo más colectivo de liderazgo.

Una vez en el poder, la idea de modernización ha sido una pieza clave para legitimar el PCCh a lo largo de la historia. Si bien el uso de la modernización como proyecto que se aspira alcanzar algún día ha estado presenta a lo largo de la historia del partido comunista, nosotros identificamos tres momentos claves que en búsqueda de esta modernización, la elite gobernante encontró medios para aumentar su control sobre las masas. El primero de ellos fue el Gran Salto hacia Adelante, el segundo la Revolución Cultural y el tercero el proceso de reforma y apertura económica conocido como las cuatro modernizaciones y el cual inició en el año de 1979.

El llamado Gran Salto hacia Adelante, entre 1958 y 1961, fue una política radical de movilización de masas que marcó un gran cambio en la aproximación de gobierno del $\mathrm{PCCh}^{34}$. Este movimiento se inspiró en la experiencia de la URSS y el objetivo fundamental era el establecimiento de comunas como unidades económicas autosuficientes; la colectivización; el trabajo en masa y la industrialización acelerada con la intención de que la producción de acero sobrepasara a la del Reino Unido en quince años ${ }^{35}$. Para ello, se desarrolló una campaña para la creación de pequeños altos hornos para la fundición de acero que debían construirse en cada comuna. Así, por ejemplo, en octubre de 1958 se informaba el gobierno se señalaba que existían un millón de estos hornos ${ }^{36}$. Las fábricas, escuelas y hospitales los trabajadores cualificados abandonaban su trabajo para destinar parte de su tiempo a producir acero. La colectivización obligatoria que reunió a los campesinos chinos en inmensas comunas destinadas a trabajos agrícolas y a la ejecución de obras ordenadas por el gobierno con la idea: extinguir el "individualismo contrarrevolucionario". La producción de alimentos fue sobredimensionada, mientras que la manipulación de cifras por parte de los gobiernos locales fue un hecho cada día más común a la vez que se sucesivamente se imponían mayores cuotas de producción. A la postre, este política causó de la muerte por inanición de millones de campesinos ${ }^{37}$.

La segunda gran transformación en China fue la llamada Revolución Cultural entre los años de 1996 hasta la muerte de Mao, en 1976. El principal objetivo para Mao fue aniquilar a sus enemigos en el PCCh. La primera tarea que se planteó fue desmantelar la burocracia y reanimar el fervor revolucionario. Para ello, se acudió a la fuerza más radical de China, los estudiantes universitarios. A ellos se les encargó que destruyeran los políticos "revisionistas" para evitar un retorno al "camino capitalista". Así, los estudiantes tomaron

\footnotetext{
${ }^{34}$ Michael Dillon, China: A Modern History, Londres, I.B. Tauris, 2010.

35 Immanuel C.Y. Hsü, The Rise of Modern China, Oxford, Reino Unido, Oxford University Press, 2000.

${ }^{36}$ Fenby, op. cit.

37 John King Fairbank y Merle Goldman, China: A New History, Cambridge, Massachusetts, Belknap Press, 2006.
} 
Daniel Carrasco - Daniel Lemus, Partido de masas y renovación de las elites: los casos de México y China / Mass party and renewal of elites: Mexico and China, Revista Izquierdas, 27, abril 2016, ISSN 0718-5049, pp. 63-86

los centros universitarios, atacaron a sus autoridades y denunciaron a funcionarios contrarios al partido de Mao. Las llamadas Guardias Rojos fueron particularmente activos en este proceso. Estos, que seguían la enseñanza de Mao de aprender la revolución haciéndola, atacaron a los monstruos y fantasmas burgueses y hundieron a China en el caos político. A fines de 1966 unos diez millones de guardias habían desfilado ante el presidente Mao para recibir su aprobación. En los últimos días, Mao había transformado el partido en una organización casi militar, dedicada al pensamiento maoísta y a la continuación de una revolución que debía ser permanente ${ }^{38}$.

Después de los años turbulentos de la Revolución Cultural era preciso emprender una serie de cambios que garantizaran recuperar el prestigio del PCCh, elevara el nivel de vida de la población y permitiera restablecer el liderazgo internacional de China en el contexto internacional. Y así como Mao había sido el líder que en nombre de la "pureza" de la ideología socialista había impulsado la Revolución Cultural, otro de los líderes del partido, Deng Xiaoping, en nombre del rescate de "un socialismo con características chinas", apelaría nuevamente al discurso modernizador para permitir la renovación de las élites al interior del partido ${ }^{39}$.

La muerte de Mao Zedong se produjo en septiembre de 1976. Con su fallecimiento, la línea conservadora del partido se vino abajo y las posibilidades de experimentar una serie de cambios en China quedaron abiertas. Así, tras la muerte de Mao, las camarilla formada por la "Banda de los Cuatro" -conformada por su esposa Qiang Qing, Zhang Chunquiao, Yao Wenyuan y Wang Hongwen-, núcleo partidario del continuismo revolucionario fue totalmente desprestigiada y años más adelante se emprendió un juicio contra ellos acusándolos de los excesos de la Revolución Cultural ${ }^{40}$.

En este punto crítico de la historia contemporánea china, los líderes del PCCh abandonaron el proyecto emanado de la Revolución Cultural y las aspiraciones derivadas de la interpretación marxista de la lucha de clases para asumir una visión muy concreta sobre el futuro de la nación: la modernización económica. Así se emprendieron las cuatro modernizaciones: Agricultura, Industria, Ejército y Ciencia y Tecnología. Evidentemente La cuestión del respeto a las libertades y la democratización del sistema político pasaban a un segundo plano, en espera de una segunda vuelta, como quedó demostrado en los trágicos sucesos de Tianamen en 1989 que culminaron con la matanza de estudiantes contrarios al régimen $^{41}$.

En la actualidad, el PCCh cuenta aproximadamente con 86 millones de miembros; cerca del 77 por ciento de sus afiliados son hombres y los campesinos constituyen alrededor de un tercio de sus miembros ${ }^{42}$. Por una parte, el PCCh es un típico régimen comunista en el cual el partido controla de manera formal e informal los niveles de poder. Pero, por otra parte, el partido contiene múltiples estructuras formales e informales inherentes a los Estados modernos. Así, a pesar a pesar de los cambios en la estructura del partido desde

\footnotetext{
${ }^{38}$ Hsü, op. cit.

${ }^{39}$ Daniel Lemus, "La modernización económica de la República Popular China: un punto de vista con una perspectiva histórica", en Juan González García, (coordinador), Perfiles Recientes del Desarrollo Económico de China, México: Universidad Autónoma Metropolitana, 2006, 51-72.

${ }^{40}$ Lemus, op. cit.

${ }^{41}$ Hsü, op. cit.

${ }^{42}$ Beina Xu y Eleonor Albert, The Chinese Communist Party, Washington, CFR Backgrounders, 2015.
} 
Daniel Carrasco - Daniel Lemus, Partido de masas y renovación de las elites: los casos de México y China / Mass party and renewal of elites: Mexico and China, Revista Izquierdas, 27, abril 2016, ISSN 0718-5049, pp. 63-86

1949 hasta el presente, ha existido una básica continuidad organizacional desde 1954 cuando los principales órganos del poder del Estado fueron establecidos.

En teoría, el partido se organiza de acuerdo con los principios del centralismo democrático que subordinan los cuadros inferiores a los niveles más altos. El resultado es un modelo jerárquico con 3 millones de organizaciones partidistas sobre la base de unidades o barrios de trabajo en la parte inferior. En la parte superior se encuentran los organismos nacionales, ubicados en la ciudad de Beijing. Nominalmente, el órgano que toma las decisiones es el supremo es el Congreso Nacional del Partido, que se reúne una vez cada cinco años. Sin embargo, a menudo la estructura de poder formal compite con las relaciones clientelares. Actualmente, el PCCh preside un complejo conjunto de políticas destinadas a desarrollar una economía basada en el mercado en combinación con un régimen autoritario fuerte y centralizado. El partido ahora es compatible con la privatización económica de facto. Al mismo tiempo, se están eliminando responsabilidades como la de la vivienda, seguro médico y las pensiones. Estas políticas están transformando la relación entre el partido y la sociedad y una preocupación central es la posibilidad de que estas medidas estén socavando profundamente por la capacidad del PCCh para controlar la sociedad en forma directa y completa como sucedía en el pasado.

El PCCh ha gobernado el país desde 1949 no tolerara ninguna oposición y con frecuencia reprime brutalmente con la disidencia. El Comité Permanente del Politburó es el órgano de decisión de mayor rango del país. El Comité Permanente se encuentra al frente de una pirámide de poder. Los miembros del Politburó nunca se han enfrentado a la elección competitivas, por lo que su posición la obtienen gracias a la red de patronazgo que los impulsa, las habilidades e instintos de supervivencia, en una cultura política donde decir algo equivocado puede conducir a una vida bajo arresto domiciliario. De manera formal, su poder se deriva de sus posiciones en el Politburó. Pero en China, país en el que las relaciones personales cuentan mucho más que los títulos, la influencia de un líder se basa en buena medida en la lealtad que construye con los superiores y protegidos. A menudo, estas relaciones se construyen durante décadas. Esta fue la manera que permitió a Deng Xiaoping a mantenerse como líder supremo después de renunciar a todas responsabilidades oficiales. Este hecho explica también porque en ocasiones los ancianos del partido juegan un papel clave en las grandes decisiones. El politburó controla otras tres órganos importantes y asegura la línea del partido se mantiene. Estos son la Comisión de Asuntos Militares, que controla las fuerzas armadas; el Congreso Nacional del Pueblo, o parlamento; y el Consejo de Estado, órgano administrativo del gobierno ${ }^{43}$.

A pesar de las reformas del mercado introducidas en China desde 1979, el Estado chino sigue siendo un sistema de inspiración marxista leninista aunque con sus propias características chinas. La parte fundamental de este sistema es el partido. El sostenimiento del PCCh en el poder se basa en tres pilares: el control de personal, la propaganda y el ejército $^{44}$. En época reciente, a pesar de los cambios estructurales económicos que han introducido una economía de mercado alejada del modelo de planeación económica centralizada, el partido busca basar su legitimidad apelando al nacionalismo y el patriotismo. Sin embargo, las fallas económicas que se han experimentado en durante el

${ }^{43}$ BBC, How Chinese is ruled, Londres, 2015

${ }^{44} \mathrm{Xu}$ y Albert, op. cit 
Daniel Carrasco - Daniel Lemus, Partido de masas y renovación de las elites: los casos de México y China / Mass party and renewal of elites: Mexico and China, Revista Izquierdas, 27, abril 2016, ISSN 0718-5049, pp. 63-86

proceso de reforma económica, han minado su legitimidad y muchos líderes han expresado en más de una ocasión que la legitimidad basada únicamente en el rendimiento económico puede erosionarse muy rápidamente. Con el partido dispuesto a redefinir públicamente su relación con otras organizaciones de la sociedad, para institucionalizar el proceso político, y ofrecer un nuevo pacto social, muchas actividades políticas ahora se lleva a cabo fuera de las estructuras formales del partido. Como sugiere Saich, para mantener su dominio, la tarea primordial para el PCCh será idear un sistema político que no es sólo una máquina de gestión eficiente, pero también uno que puede acomodar a las demandas de una sociedad cada vez más compleja ${ }^{45}$.

En este contexto, el PCCh se sometió en el año 2012 a una transición fundamental al generar las condiciones para el arribo al poder de la quinta generación de líderes. En el marco del XVIII Congreso Nacional se eligió la generación de líderes que se espera gobiernen China hasta 2022. La Comisión Permanente se redujo de nueve a siete miembros. En este proceso el vicepresidente Xi Jinping remplazó al Hu Jintao como Presidente y el viceprimer Li Keqiang ocupó el cargo de Primer Ministro que estaba en manos de Wen Jibao. Asimismo, alrededor del 70 por ciento de los miembros de los tres órganos del partido- Comité Permanente, Consejo de Estado y Centro Militar- fueron remplazados, por lo que esta transición constituyó el cambio más significativo en las últimas tres décadas del liderazgo en China ${ }^{46}$.

El PCCh se reúne el Congreso Nacional del Partido (APN) cada cinco años para establecer las principales políticas y elegir al Comité Central, que comprende alrededor de 370 miembros, entre ellos ministros, funcionarios de alto rango de regulación, líderes provinciales y oficiales militares. El Comité Central actúa como una especie de junta directiva para el PCCh, y su mandato es seleccionar el Politburó, que cuenta con veinticinco miembros. A su vez, el Politburó elige a través de negociaciones a puerta cerrada del Comité Permanente que funciona como el epicentro del poder y el liderazgo del PCCh.

Actualmente, Xi Jinping, se encuentra en la cima del sistema como Secretario General del Partido; como Presidente y como Jefe de las Fuerzas Armadas. Él establece una enorme influencia en el establecimiento de los parámetros de la política de gobierno. El primer ministro, Li Keqiang, encabeza el Consejo de Estado, equivalente a un gabinete de China. En la transición de $\mathrm{Xi}$ al poder, ha acumulado más poder que sus predecesores; como el único cabeza de un número de grupos líderes importantes, su toma de decisión unilateral ha socavado en cierta medida el compromiso antes de su partido de gobierno basado en el consenso.

\section{b) La fundación del PRI y la renovación de la elite posrevolucionaria}

Después del periodo revolucionario (1910-1917), México vivió bajo el régimen de los caudillos militares. La lucha por el poder presidencial entre los grupos de militares y civiles que participaron en la revolución, así como el asesinato de Álvaro Obregón en julio de

\footnotetext{
45 Tony Saich, "Chinese Communist Party", En Joel Krieger, (editor), The Oxford Companion to Politics of the World, Oxford, Reino Unido, Oxford University Press, 2001

46 Xu y Albert, op. cit
} 
Daniel Carrasco - Daniel Lemus, Partido de masas y renovación de las elites: los casos de México y China / Mass party and renewal of elites: Mexico and China, Revista Izquierdas, 27, abril 2016, ISSN 0718-5049, pp. 63-86

1928, quien había sido reelegido a la presidencia de la República en 1928, obligó al presidente Plutarco Elías Calles, el 1 de septiembre de 1928 a crear un partido único que fuera el mecanismo capaz de unificar todas las fuerzas revolucionarias que habían sido parte de las grupos armados revolucionarias que habían combatido contra las estructuras del Antiguo Régimen y que, una vez derrotado el régimen reaccionario, se habían enfrentado entre sí por alcanzar el poder presidencial.

En su mensaje del 1 de diciembre de 1928, Calles explicaba la necesidad de construir un partido de la revolución, pero esta necesidad, no solamente provenía de la difícil coyuntura por la cual pasaba la vida política nacional mexicana, sino también del círculo de amigos y sobre todo del grupo gobernante.

En 1928, después de haber logrado el cambio de leyes sobre la no reelección presidencial, el presidente Álvaro Obregón ganó una vez más las elecciones presidenciales, pero antes de tomar posesión fue asesinado, después de este hecho tres presidentes se sucedieron sin haber terminado su periodo presidencial: Emilio Portes Gil, Pascual Ortiz Rubio y Abelardo Rodríguez. Este periodo es conocido como el maximato puesto que durante este periodo el poder fue concentró en el jefe máximo, Plutarco Elías Calles. La influencia de Calles se terminó cuando el general Cárdenas llegó a la presidencia y lo expulsa del país ${ }^{47}$.

Con el objetivo de constituir un comité organizador del nuevo partido, en noviembre de 1929, el presidente Calles reunió un grupo de 20 personas escogidas por él mismo, entre ellos se encontraba Emilio Portes Gil, quien un mes después accedió a la presidencia provisoria que duró 14 meses. El mismo día, el 1 de diciembre de 1928, el comité organizador del Partido Nacional Revolucionario convocó a todos los revolucionarios. Esta convocatoria de 1929 se tradujo en la primera reunión de líderes revolucionarios y el objetivo principal fue escoger al candidato a la presidencia, quien tendría el total apoyo de todas las fuerzas políticas que participaron en la revolución.

En este contexto, es importante señalar que después de la Revolución (1910-1917), todas las fuerzas políticas buscaban reunirse en un esquema de control centralizado. Por lo tanto, existía una verdadera necesidad de adaptar un poder presidencial fuerte para combatir estos elementos, pero también para hacer una vida política nacional más civilizada. La falta de integración, dada la revolución y la existencia de grupos oligárquicos locales y regionales, no permitió la modernización del Estado. La creación del Partido Nacional Revolucionario (PNR) en 1929, tuvo como objetivo principal llenar ese espacio vacío, integrando diversos grupos ya organizados $\mathrm{y}$, a su vez, organizando a aquellos que aún no lo estaban. Es de esta forma que el PNR es el resultado de una coalición de fuerzas militares y civiles, de campesinos y de obreros, con el objetivo de combatir las desigualdades, tomando el compromiso de luchar contra la injusticia social. Es decir, desde la perspectiva de colocar a México en el camino de la modernización entendida como la posibilidad de alcanzar el progreso para la inmensa mayoría de los explotados y desposeídos que habían sido ignorados durante el periodo del Antiguo Régimen. Así, se impuso la tarea de la desmilitarización de la política y la modernización de la sociedad, asumiendo de esta manera una dimensión política sin precedente en la historia de México. En otras palabras, se trataba de una búsqueda paralela por alcanzar la modernidad política y

47 Arnaldo Córdoba, La revolución en crisis: la aventura del maximato, México, D.F., Cal y Arena, 1994. 
Daniel Carrasco - Daniel Lemus, Partido de masas y renovación de las elites: los casos de México y China / Mass party and renewal of elites: Mexico and China, Revista Izquierdas, 27, abril 2016, ISSN 0718-5049, pp. 63-86

la modernidad social.

Es así como después de 1929, el PNR jugó un rol de partido casi-monopolio, dirigiendo la política nacional a través de la creación de diversas instituciones que reunieron a todos los sectores de la sociedad. Entre esos sectores se encontraban los campesinos -a través de la Confederación Nacional Campesina (CNC)-, obreros y trabajadores en general -agrupados en Confederación de Trabajadores de México (CTM)y, por supuesto las organizaciones populares, -bajo la tutela de la Confederación de Organizaciones Populares (CNOP).

En 1938 el partido emanado de la Revolución sufrió su primera transformación, convirtiéndose en el Partido de la Revolución Mexicana (PRM). Esta transformación lo constituyó como un auténtico partido de Estado, organizando a las masas populares y dando a todos los líderes políticos un apoyo nacional y, más importante aún, un apoyo "institucionalizado". Esta transformación dirigida por el presidente de la República a través del Estado dio una nueva base de legitimación del poder político en México reforzando la institución presidencial ${ }^{48}$. Esto ocurrió durante el primer periodo presidencial de seis años, el sexenio del general Lázaro Cárdenas del Río.

En 1946 el PRM se transformó una vez más: se convirtió en el Partido Revolucionario Institucional (PRI). El nuevo objetivo fue extender sus bases a todo el territorio nacional, a la vez que se pretendió empujar el desarrollo y la democracia, así como mantener la estabilidad y la paz social ${ }^{49}$. Pero más allá de este cambio significativo se distingue la llegada de los civiles a la presidencia de la República y con ello el desplazamiento de los militares del poder presidencial. En este mismo año Miguel Alemán llegó a la presidencia. Jurista de formación, había sido gobernador del estado de Veracruz y secretario de Gobernación del gobierno precedente de Manuel Ávila Camacho, se distinguió entonces de los presidentes anteriores por el simple hecho de contar con un diploma universitario de derecho, lo que marcó una distinción en relación con el perfil profesional de los presidentes anteriores egresados del Colegio Militar y miembros activos del movimiento revolucionario.

Cuando Miguel Alemán conforma su gobierno, se generó una gran polémica, ya que la mayoría de los secretarios eran jóvenes universitarios y como su jefe, tampoco habían participado en la revolución. El hecho de que el nuevo gobierno se integrara por jóvenes universitarios y por algunos profesores, mostraba lo importante del proceso de selección del personal gubernamental y además que la política mexicana comenzaba a profesionalizarse. El mérito profesional parecía reemplazar las preferencias personales y políticas, de esta forma los antecedentes revolucionarios dejaron de jugar un rol importante en el proceso de selección de los miembros del gobierno y, por lo tanto, era el signo de la madurez y de la modernidad del grupo en el poder político en México. Este periodo fue considerado como el del civilismo político.

Se creía que con la llegada de los universitarios al poder político, podía aumentar la eficacia del régimen, y había una confianza para sanar la vida política mexicana reduciendo

\footnotetext{
48 Luis Javier Garrido, El Partido de la Revolución Institucionalizada. La formación del Nuevo Estado en México (19281945), México, D.F., Siglo XXI, 1995

49 Pedro Aguirre, Alberto Begné y José Woldenberg, Sistemas políticos, partidos y elecciones, México, D.F.: Trazos, 1997.
} 
Daniel Carrasco - Daniel Lemus, Partido de masas y renovación de las elites: los casos de México y China / Mass party and renewal of elites: Mexico and China, Revista Izquierdas, 27, abril 2016, ISSN 0718-5049, pp. 63-86

la corrupción. Al mismo tiempo se esperaba que los egresados serían menos susceptibles a la corrupción, pero la experiencia ha demostrado lo contrario. La expansión de la industria y de la economía impulsada por el gobierno de Alemán, estuvieron acompañadas de una corrupción sin precedentes.

Alemán escogió como sucesor a Ruiz Cortines (1952-1958), que aunque alcanzó la cima del sistema político, de la misma manera que Alemán, ocupando puestos en la burocracia política así como en el PRI. Contaba también con la experiencia electoral, había ocupado puestos de elección popular como diputado y gobernador del estado de Veracruz, como su predecesor antes de ser candidato a la presidencia, también participó en la lucha armada y obtuvo el rango militar de mayor. Los miembros de su gobierno contaban con varias similitudes con respecto a sus predecesores, puesto que muchos de ellos eran abogados formados en la UNAM; sin embargo, tenían la ventaja de contar con la experiencia en puestos de la burocracia ${ }^{50}$. Este hecho marcó un cambio importante en la elite política en México en relación con sus predecesores, quienes habían participado en la lucha armada y pertenecido a los equipos de gobierno de los presidentes militares. Entonces en esta época, el perfil y la trayectoria de la elite política cambia, pasando de un trayecto militar revolucionario, a un trayecto burocrático y profesionalizado.

Adolfo López Mateos ocupó la presidencia de la República de 1958 a 1964. Sucesor de Ruiz Cortines, abogado con una gran experiencia en las esferas burocráticas y partidistas antes de ser candidato a la presidencia. En lo que concierne al nivel de estudios de sus secretarios de Estado contaban con el mismo perfil de los dos gabinetes anteriores, abogados egresados de la UNAM, su trayectoria en la burocracia y en el PRI eran sus características fundamentales. Su sucesor, Gustavo Díaz Ordaz (1964-1970) había sido secretario de Gobernación antes de ser candidato del PRI a la presidencia. También ex alumno de la Facultad de Derecho de la UNAM y como sus predecesores, ocupó puestos de elección popular, diputado y senador del estado de Puebla, así como en la burocracia federal. La gran parte de su equipo de gobierno no tenía la experiencia académica ni profesional que él contaba. Ello deja ver que no hubo ningún cambio en relación con el periodo presidencial anterior.

En 1969, Díaz Ordaz escogió a Luis Echeverría que ocupó la presidencia entre 1970 y 1976. Echeverría difiere de sus predecesores, no contaba con ninguna experiencia electoral antes de iniciar su campaña por la presidencia ${ }^{51}$. Inició su carrera burocrática muy joven y en puestos de gran importancia en la Secretaría de Educación Pública y en la de Gobernación. Contaba con una red de amigos muy bien posicionada en los altos puestos burocráticos, desde el inicio de su carrera política siempre muy cercano a ex secretarios de Estado y próximos presidentes. Lo que puede explicar su nominación como candidato del PRI a la presidencia. Echeverría ocupó el puesto de secretario de Gobernación del gobierno de Díaz Ordaz. Él fue quien dirigió la represión de los estudiantes en 1968, razón por la cual su elección a la presidencia fue cuestionada. A pesar de ello, Echeverría realizó grandes esfuerzos para alejarse del gobierno anterior, buscando el olvido de los hechos del 68 y consolidando su poder como presidente ${ }^{52}$.

\footnotetext{
50 Juan D. Lindau, Los tecnócratas y la élite gobernante mexicana, México, D.F., Joaquín Mortiz, 1992.

51 Lindau, op. cit.

52 Jorge G. Castañeda, La herencia: arqueología de la sucesión presidencial en México, México, D.F., Alfaguara, 1999.
} 
Daniel Carrasco - Daniel Lemus, Partido de masas y renovación de las elites: los casos de México y China / Mass party and renewal of elites: Mexico and China, Revista Izquierdas, 27, abril 2016, ISSN 0718-5049, pp. 63-86

Entre 1976 y 1982, López Portillo ocupó la presidencia, designado por Echeverría como candidato del PRI siendo amigo de la juventud de su predecesor y ex secretario de Estado de Hacienda. De la misma manera que Echeverría, no contaba con experiencia electoral antes de su candidatura por la presidencia y había hecho su carrera en la burocracia. Se pensaba que Echeverría lo había escogido como su sucesor para poder continuar con la dirección del país. En cuanto llega López Portillo a Los Pinos demuestra una gran independencia con respecto a su ex jefe $\mathrm{e}^{53}$.

La conformación del gobierno de la Madrid fue presentado como un alternativa para resolver los problemas financieros que México enfrentaba en aquella época. Los cambios en la jerarquía gubernamental en relación con el gobierno anterior fueron significativos sobre todo en el sector económico. El nuevo presidente eliminó la estructura gubernamental anterior, algunos ministerios tales como el de Patrimonio Nacional, Obras Públicas, el Departamento de la Industria Militar, el Departamento de Pesca. Estos cambios reflejaban el interés del nuevo jefe de gobierno por poner en marcha una nueva política económica, iniciando por dar una nueva imagen de la elite política y por lo tanto con un nuevo liderazgo. Destaca en este periodo la renuncia de Carlos Salinas de Gortari al puesto de secretario de Planeación y Presupuesto y se convierte en el candidato del PRI a la presidencia; su cargo como secretario lo ocupa Pedro Aspe Armella, futuro Secretario de Economía de su gobierno.

Carlos Salinas de Gortari ganó la presidencia con el índice más bajo jamás registrado por este partido 50.1 por ciento, contra 30.5 por ciento del FDN (Frente Democrático Nacional, antecedentes del PRD) ${ }^{54}$ y 16.7 por ciento del PAN. La escena política mexicana en esta época era extremadamente compleja, por un lado, el nuevo presidente carecía de legitimidad y, por otro lado, los dos principales partidos de oposición, PAN y FDN obtuvieron en las elecciones de 1988, por primera vez casi la mayoría absoluta de la Cámara de Diputados 47.1, 18 y 29 por ciento, respectivamente, lo que representa para los 500 curules que componen la cámara de diputados 101 asientos para el PAN y 139 para el FDN y 260 para el PRI. Salinas llegó a la presidencia bajo condiciones muy difíciles, heredó un sistema económico y político demasiado alejado de la realidad mexicana. Además, la mayoría de la oposición no lo reconocía como un presidente elegido de manera legítima y, por lo tanto, una parte de la ciudadanía desconfiaba de él. En ese contexto, una de las prioridades de Salinas fue conformar un gabinete estable y competente, capaz de legitimar las acciones del jefe del gobierno mexicano.

Ernesto Zedillo fue elegido presidente en circunstancias dramáticas. Después del asesinato de Luis Donaldo Colosio, candidato del PRI a la presidencia, el 23 de marzo de 1994 en Tijuana en el estado de Baja California, Zedillo, quien era el coordinador de campaña de Colosio, lo reemplaza convirtiéndose en el segundo candidato del PRI a la presidencia; la sociedad mexicana tenía miedo y el voto contra la violencia en las elecciones de julio de 1994 le da la victoria. El 1 de diciembre de 1994, asume la presidencia de México, con 78 por ciento votos, siendo un porcentaje sin precedente.

53 Roderic Ai Camp, Reclutamiento político en México, 1884-1991, México: Siglo XXI, 1996.

54 Este frente se constituyó a partir de la alianza de cuatro partidos: Partido Auténtico de la Revolución Mexicana (PARM), el Partido Popular Socialista (PPS), el Partido Mexicano Socialista (PMS) y el Partido Frente Cardenista de Reconstrucción Nacional (PFCRN). 
Daniel Carrasco - Daniel Lemus, Partido de masas y renovación de las elites: los casos de México y China / Mass party and renewal of elites: Mexico and China, Revista Izquierdas, 27, abril 2016, ISSN 0718-5049, pp. 63-86

Por otro lado, la aparición de la guerrilla en el estado de Chiapas el 1 de enero de 1994 podría degenerar en una verdadera guerra civil en este estado de la República mexicana. En el plano económico, en diciembre de 1995, el peso mexicano sufre una fuerte devaluación frente al dólar americano, lo que generó una disminución significativa en el poder adquisitivo de los mexicanos. El objetivo principal del nuevo gobierno fue encontrar las soluciones a estos problemas a través de nuevos programas de gobierno. El contexto obliga al gobierno de Zedillo a constituir un equipo de gobierno capaz de tomar decisiones difíciles. Durante el gobierno de Zedillo, se realizaron 32 cambios ministeriales. Solamente cuatro de los 29 secretarios designados al inicio del mandato presidencial permanecieron en su puesto original y por lo tanto 25 cambiaron, hubo en total 52 nominaciones.

Del 2000 al 2012 la elite política del PRI que venía gobernando desde la década de los veinte, quedó excluida de la elite política federal, durante este periodo se sucedieron dos periodos presidenciales del mismo partido PAN, el primero liderado por el presidente del "cambio político" Vicente Fox, así se le denominó y el segundo por Felipe Calderón, ambos que a pesar de haber aprovechado las luchas internas del PRI que habían desgastado su capacidad de competencia electoral lograban ganar las elecciones presidenciales y ambos obtienen en general un desempeño muy pobre en relación con las expectativas de la ciudadanía.

A pesar de dos sexenios en los que la presidencia de la República fue ocupada por el PAN en el año 2012 las elecciones presidenciales permitieron el regreso del PRI al poder. Sin embargo, es importante señalar que durante esos doce años el PRI mantuvo el control a nivel regional en las distintas entidades estatales. En otras palabras, la retirada del poder central no significó la pérdida de apoyo en amplias zonas geográficas del país, particularmente en el centro y sur del país. Es a partir de estas estructuras regionales como se reacomodan las fuerzas políticas al interior del partido que permiten el regreso del PRI al poder. En este contexto, particularmente significativo es el llamado grupo Atlacomulco que operó desde las bases priistas del Estado de México, en el centro del país. De esta manera, complementada por una relación muy estrecha con los medios de comunicación y a partir del consenso generado en los distintos grupos priistas en diferentes regiones de México, se constituyó una imagen mediática que eventualmente permitió el regreso del PRI al poder.

Los procesos de cambio y permanencia de las élites del poder en México se pueden explicar a través del fenómeno presidencial mexicano por lo tanto es fundamental entender el método que tiene el modo de elección del presidente en México; éste puede ser concebido a través de dos lógicas distintas, la primera está vinculada a la constitución y la segunda (no constitucional) esta relacionada con el PRI y el presidente saliente. En la primera como lo dice la constitución (Art. 81), la elección del Presidente es una elección por sufragio directo, secreto y universal, la duración de su mandato es de seis años y no puede ser reelegido. En la segunda; el candidato del PRI a la presidencia es elegido por el presidente saliente. Este método de designación fue conocido como el "dedazo", de esta forma el partido pone en marcha todo su aparato corporativo para garantizar la victoria electoral. Aplicado desde sus orígenes (1929), este método se volvió una tradición política sexenal, pero en el 2000 durante la presidencia de Zedillo, el método de selección del candidato cambió.

Se organizó una elección nacional para elegir al candidato, en esta elección los

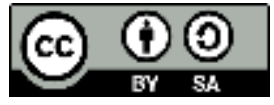


Daniel Carrasco - Daniel Lemus, Partido de masas y renovación de las elites: los casos de México y China / Mass party and renewal of elites: Mexico and China, Revista Izquierdas, 27, abril 2016, ISSN 0718-5049, pp. 63-86

votantes eran solamente militantes del PRI, es así como Francisco Labastida Ochoa se convirtió en candidato a la presidencia en el 2000, a pesar del esfuerzo del presidente Zedillo para modernizar y legitimar el modo de elección del candidato, la mayoría de la población no creyó en esta nueva versión democrática del PRI. Por lo tanto existió una preeminencia del presidente sobre el partido. Por otro lado, la concepción sobre la duración del mandato presidencial en México es la de Anne Pivron, quien explica que la duración del mandato presidencial mexicano se sostiene sobre el principio de la maximización de los recursos del presidente de la República y su no reelección, de hecho constituye la limitación de su poder.

Como miembros de la elite política gobernante los secretarios de estado en México son elegidos a partir de criterios específicos, pero dicha elección depende ante todo de la confianza que ellos inspiran al jefe del gobierno para resolver los problemas de la población, es decir del presidente. Los criterios de elección en México, en general, para ser susceptible a ocupar un puesto de secretario de Estado es necesario estar cerca del presidente, pertenecer a su medio o ambiente administrativo y ser parte del grupo de amigos, ocupar un puesto de subsecretario de Estado, contar con un perfil más o menos neoliberal (desde 1982), y una afiliación priísta (hasta el 2000). Posteriormente, durante los sexenios de Vicente Fox y Calderón los criterios cambian pues son presidentes del partido de oposición, PAN Partido Acción Nacional, situado a la derecha del espectro político mexicano; y en el 2012, con la elección de Enrique Peña Nieto el formato de elección de los miembros de la elite política siguen la lógica de los gobiernos priistas anteriores.

\section{Conclusiones}

En general, se puede afirmar que los antecedentes de la elite política actual en México encuentran sus orígenes en dos distintos momentos históricos posrevolucionarios. El primero, ocupa el periodo previo a la llegada del general Lázaro Cárdenas en donde la elite gobernante y el partido de la revolución dependía directamente del jefe máximo de la revolución, Plutarco Elías Calles; el segundo periodo se refiere a la llegada de Cárdenas a la presidencia en 1935 y precisamente con la ruptura que tuvo con el jefe máximo Calles en donde se remplaza el liderazgo personalizado por un liderazgo institucional. Esta fue la fórmula que permitió generar la estabilidad del régimen y la renovación de las elites en un periodo perfectamente establecido, en el que todos los actores y todos los aspirantes, tenían con claridad las reglas de la transición de la unidad al interior del partido. De esta manera, la conformación de la elite política actual, se deriva del modelo de liderazgo institucional, instrumentalizado por el partido de la revolución y por supuesto del presidente en turno.

En el caso del PCCh se encuentran con claridad dos periodos que marcan también la vida del partido en forma similar. El primero de estos periodos es el que encabezó el máximo líder de la Revolución Comunista, Mao Zedong. Mao se convirtió en el líder absoluto del partido aún antes del triunfo del comunismo, a finales de la década de 1930 y hasta su muerte en el año de 1976. Si bien existieron algunos momentos en que la misma cúpula del partido pretendió al menos limitar su poder absoluto, como ocurrió después del fracaso estrepitoso del proyecto de industrialización conocido como El Gran Salto hacia Adelante, es un hecho que el poder en China se pensó, se ejerció, se monopolizó y se 
Daniel Carrasco - Daniel Lemus, Partido de masas y renovación de las elites: los casos de México y China / Mass party and renewal of elites: Mexico and China, Revista Izquierdas, 27, abril 2016, ISSN 0718-5049, pp. 63-86

concretizo en y alrededor de Mao Zedong. La evidencia histórica demuestra que la China postrevolucionaria fue una Estado totalitario, con un culto absoluto al que en muchos sentidos puede ser considerado el último emperador de China, Mao Zedong. En este contexto, el partido no fue un contrapeso a Mao, sino el instrumento por el cual se concretizaron las medidas que desde la cúpula del poder se pensaban para toda China. Las decisiones más importantes estaban en las manos de Mao y de la camarilla que lo rodeaba, siempre a su sombra.

Sin embargo, a la muerte de Mao se abrió la posibilidad de la renovación de la elite. En un periodo de transición que duró tres años, de manera silenciosa Deng Xiaoping, quien sobrevivió a dos purgas del partido, surgió como el nuevo líder de China. Lo interesante de este proceso es que en un proceso gradual y pragmático, de ser un partido en muchos sentido caudillista - a semejanza del PRI cuando fue fundado- el PCCh ha transitado a un régimen más institucionalizado. Esta institucionalización se evidencia la renovación de las elites a partir de lo que se ha nombrado las distintas generaciones del poder en China. La llegada de la quinta generación al poder en el año del 2012 muestra que si bien, al igual del PRI, al interior existen fricciones entre las diversas facciones del poder, una vez que este es asumida por la nueva elite existen los mecanismos al interior que permiten fortalecer el poder de la nueva elite como resultado de una institucionalización asumida por las nuevas dirigencias.

En conclusión, es posible afirmar que la razón clave de que esto suceda así se desprende del hecho de la creación de un discurso modernizador como fuente de legitimidad política del régimen. De esta manera, es la bandera de la modernización -del partido, de la vida política y de la nación misma- la que ha sido enarbolada como el principal elemento de justificación y cohesión al interior del partido. Así la institucionalización de ambos partidos ha sido impulsada por este discurso justificando la acción política y la renovación necesaria de sus elites.

\section{Bibliografía}

Aguirre Pedro, Begné Alberto y Woldenberg José, Sistemas políticos, partidos y elecciones, México, D.F.: Trazos, 1997

Bobbio Norberto et al., "Teoría de las elites", en Diccionario de Política, México, D.F., Siglo XXI, 2006.

Camp Roderic Ai, Reclutamiento político en México, 1884-1991, México: Siglo XXI, 1996.

Castañeda Jorge G., La herencia: arqueología de la sucesión presidencial en México, México, D.F., Alfaguara, 1999.

Chagnollaud Dominique, "Les théories des élites", en Sociologie Politique, París, Dalloz, 2000.

Córdoba Arnaldo, La revolución en crisis: la aventura del maximato, México, D.F., Cal y Arena, 1994 
Daniel Carrasco - Daniel Lemus, Partido de masas y renovación de las elites: los casos de México y China / Mass party and renewal of elites: Mexico and China, Revista Izquierdas, 27, abril 2016, ISSN 0718-5049, pp. 63-86

Córdova, Marycela, "Modernidad, cultura y devenir del mundo actual", en Zidane Zaraoui (compilador), Modernidad y Posmodernidad: la crisis de los paradigmas y los valores, México, D.F, Editorial Limusa, 2000, 135-159.

Dahl, Robert, Who Governs?: Democracy and Power in an American City. New York, Yale University Press, 1961.

Dillon Michael, China: A Modern History, Londres, I.B. Tauris, 2010.

Duverger Maurice, Los partidos políticos, México, D.F., Fondo de Cultura Económica, 1957.

Ellis Elisabeth, "Modernity: Overview” en New Dictionary of History of Ideas, Detroit, Charles Scribner's Sons, 2005.

Evans Harriet, Historia de China desde 1800, México, D.F., El Colegio de México, 1989.

Fairbank John King y Goldman Merle, China: A New History, Cambridge, Massachusetts, Belknap Press, 2006.

Fenby Jonathan, History of Modern China: The Fall and Rise of a Great Power, 1850 to the present, Londres, Penguin Books, 2013.

Garrido Luis Javier, El Partido de la Revolución Institucionalizada. La formación del Nuevo Estado en México (1928-1945), México, D.F., Siglo XXI, 1995.

Habermas Jürgen, "Modernidad, un proyecto incompleto", en Nicolás Casullo (ed.), El Debate Modernidad Posmodernidad, Buenos Aires, El Cielo por Asalto, 1995, 131-144.

Hsü Immanuel C.Y., The Rise of Modern China, Oxford, Reino Unido, Oxford University Press, 2000

Krauze Enrique, La presidencia Imperial, México, D.F., TuQuest Editores, 2002

Lafleur Robert André, "History". En Robert André Lafleur, (ed.), Asia in Focus: China, Santa Barbara, California, ABC-Clio, 2010, 21-66

Lawrence Alan, China under Communism, Londres, Routledge, 1998

Le Goff Jaques, Pensar la historia: modernidad, presente, progreso, Barcelona, Paidos, 1997

Lemus Daniel, "La modernización económica de la República Popular China: un punto de vista con una perspectiva histórica", en Juan González García, (coordinador), Perfiles Recientes del Desarrollo Económico de China, México: Universidad Autónoma Metropolitana, 2006, 51-72

Lieberthal Kenneth, Governing China: From Revolution through Reform, Nueva York, W.W. Norton \& Company, 1995

Lindau Juan D., Los tecnócratas y la élite gobernante mexicana, México, D.F., Joaquín Mortiz, 1992

Michels, Robert, Les Partis politiques: essai sur les tendances oligarchiques des démocraties, París, Flammarion, 1971 
Daniel Carrasco - Daniel Lemus, Partido de masas y renovación de las elites: los casos de México y China / Mass party and renewal of elites: Mexico and China, Revista Izquierdas, 27, abril 2016, ISSN 0718-5049, pp. 63-86

Mills, L'élite du pouvoir, París, F. Maspero, 1969.

Palmwosky Jan, "Communist Party: China", en A Dictionary of Contemporary World History, Oxford, Reino Unido, Oxford University Press, 2008

Saich Tony, "Chinese Communist Party", En Joel Krieger, (editor), The Oxford Companion to Politics of the World, Oxford, Reino Unido, Oxford University Press, 2001

Schell, Orville y Delury John, Wealth and Power: China's Long March to the Twenty First Century, Nueva York, Random House, 2013

Spence, Jonathan D., The Search of Modern China, Nueva York: W.W. Norton \& Company, 1999

Touraine Alain, Crítica de la Modernidad, México, D.F., Fondo de Cultura Económica, 2002

Uhalley Stephen, A History of the Chinese Communist Party, Stanford, California, Stanford University Press, 1988

Zang Xiaowei, "Government and changing social relations", en Xiaowei Zang, (ed.), Understanding Chinese Society, Londres, Routledge, 2013, 170-182

\section{Sitios electrónicos:}

BBC, How Chinese is ruled, Londres, 2015. Disponible en: http://news.bbc.co.uk/2/shared/spl/hi/in_depth/china_politics/government/html/1.stm

$\mathrm{Xu}$ Beina $\mathrm{y}$ Eleonor Albert, The Chinese Communist Party, Washington, CFR Backgrounders, 2015. Disponible en: http://www.cfr.org/china/chinese-communistparty/p29443?cid=ppc-Google-grant-backgrounder-

chinese communist_party\&gclid=Cj0KEQjwvo6wBRCG3Zv92ZSLIIYBEiQA5PLVAjpo xDuWn5LtHleYv1HiLdfS_7GtHjuX31JnzrPVjPwaAvxW8P8HAQ 